\title{
Percutaneous Dorsal Approach for Fractures of the Hook of the Hamate: A Less Common but Effective Option
}

\section{Abordaje Dorsal Percutáneo para las Fracturas del Gancho del Ganchoso: Una Alternativa Menos Común Pero Eficaz}

\author{
Borja Occhi Gómez ${ }^{1,2}$ Ángel García Olea ${ }^{2}$ Virginia Herrero Sierra ${ }^{2}$
}

${ }^{1}$ Hospital Universitario Rey Juan Carlos, Móstoles, Spain

2 Hospital Universitario Puerta de Hierro, Majadahonda, Spain

Rev Iberam Cir Mano 2021;49(2):e90-e96.
Address for correspondence Borja Occhi Gómez, MD, Servicio de Cirugía Ortopédica y Traumatología, Hospital Universitario Rey Juan Carlos, Calle Gladiolo s/n, 28933, Móstoles, Spain

(e-mail: borjaocchi@gmail.com).

\section{Abstract}

Keywords

- hamate fracture

- hook of hamate fracture

- hook of hamate

- hamate

Introduction Hook of hamate fractures are rare. The best treatment option is a source of debate; it ranges from conservative to surgical techniques, including resection of the hook or a volar approach followed by internal fixation. These techniques are not exempt from risk. Minimal invasive fixation using a dorsal percutaneous approach and a headless, cannulated mini screw is another option, although not commonly considered. We present a case series of patients who underwent this surgical technique.

Methods This is a retrospective review of four patients with nondisplaced hook of hamate fractures treated with dorsal percutaneous fixation. The evaluation included symptoms, physical examination, and radiological (radiographs, magnetic resonance imaging [MRI], and computed tomography [CT]) findings, as well as pre and postoperative strength (determined with a Jamar (JLW Instruments, Chicago, USA) hydraulic dynamometer) and quick disabilities of the arm, shoulder and hand (QuickDASH) scores.

Results The union rate was $100 \%$ with no associated complications. All patients resumed their preinjury activities 3 months after the surgery and reported they would undergo surgery again if needed.

Conclusion This retrospective study shows that safe treatment of nondisplaced hook of hamate fractures with percutaneous dorsal fixation is feasible, with excellent clinical outcomes. In any case, our sample is limited, and further studies are required.
\end{abstract}

received

June 17,2020

accepted

March 25, 2021
DOI https://doi.org/ $10.1055 / \mathrm{s}-0041-1741322$ ISSN 1698-8396.

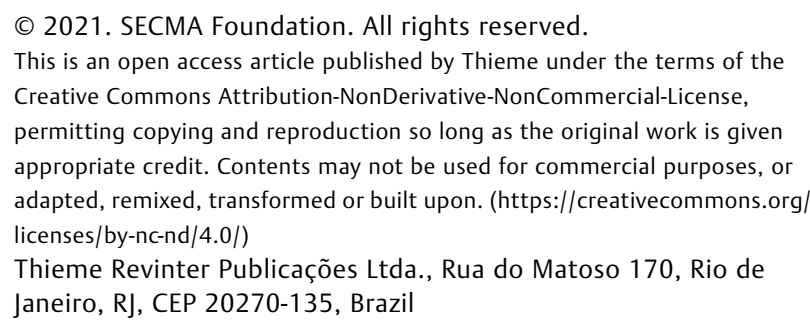
Creative Commons Attribution-NonDerivative-NonCommercial-License, permitting copying and reproduction so long as the original work is given appropriate credit. Contents may not be used for commercial purposes, or adapted, remixed, transformed or built upon. (https://creativecommons.org/ licenses/by-nc-nd/4.0/)

Thieme Revinter Publicações Ltda., Rua do Matoso 170, Rio de Janeiro, RJ, CEP 20270-135, Brazil 


\section{Resumen}

\section{Palabras Clave}

- fractura del ganchoso

- fractura del gancho del ganchoso

- gancho del ganchoso

- ganchoso
Introducción Las fracturas del gancho del ganchoso son infrecuentes. Se debate el tratamiento óptimo, desde el conservador hasta técnicas quirúrgicas, que incluyen la resección del gancho o un abordaje volar y fijación interna. Estas técnicas no están exentas de riesgo. Una alternativa reciente y segura es la fijación interna mediante un abordaje dorsal percutáneo. Presentamos una serie de casos de pacientes a los que se aplicó esta técnica en fracturas agudas o con retrasos de unión.

Métodos En este estudio, se han revisado 4 pacientes con fracturas del gancho del ganchoso no desplazadas, de hasta 9 meses de evolución, intervenidos mediante una fijación percutánea dorsal. Se revisó la sintomatología, la exploración física, y la radiología (radiografías, resonancia magnética [RM] y tomografía computarizada [TC]). Se evaluó la fuerza de presión mediante el dinamómetro de Jamar (JLW Instruments, Chicago, USA) y el puntaje en la versión corta del cuestionario de Discapacidades del Brazo, Hombro y Mano (Quick Disabilities of the Arm, Shoulder and Hand, Quick DASH, en inglés) pre y postoperatorios.

Resultados En el 100\% de los casos, se consiguió la unión de la fractura, sin complicaciones asociadas. En tres de los cuatro casos, la fractura ocurrió en la mano no dominante. Todos los pacientes volvieron a su actividad habitual tres meses después, y declararon que volverían a operarse con esta técnica si fuera necesario.

Conclusión Este estudio retrospectivo muestra que las fracturas no desplazadas del gancho del ganchoso pueden intervenirse mediante una fijación percutánea dorsal, de forma segura, con un resultado clínico excelente. En todo caso, nuestra muestra es limitada, y deben realizarse más estudios.

\section{Introduction}

Hook of hamate fractures are rare, accounting for 2 to $4 \%$ of carpal fractures. ${ }^{1-3}$

These fractures usually occur after direct trauma to the hook of hamate; in addition, they can result indirectly from sudden contraction of the fourth and fifth fingers or repeated microtrauma. Because of the injury mechanism, this type of fracture occurs frequently among individuals who practice sports that require a strong grip, and they occur more often in the non-dominant hand. ${ }^{4-6}$

The diagnosis of hook of hamate fracture is often delayed due to difficulty in identifying the lesion in plain radiographs. ${ }^{4,7,8}$ The most common clinical signs include ulnar pain in the wrist that worsens when grasping objects, pain during hook of hamate palpation, and a positive pull test. ${ }^{5}$

The best course of treatment is controversial. Conservatively treated fractures present a high rate of pseudoarthrosis, resulting from poor vascularization and stresses imposed on the hook of hamate due to its close relationship with the flexor muscles of the fourth and fifth fingers. ${ }^{4,9,10}$ Pseudarthrosis can lead to chronic wrist pain, carpal tunnel syndrome, ulnar canal syndrome, or tendon tears. ${ }^{11}$

Surgical treatment is often reserved for displaced fractures, painful non-unions, or athletes; classical techniques include hook resection or open reduction and internal fixation. In the last decade, the introduction of minimally invasive percutaneous techniques using cannulated screws led to functional and radiological outcomes similar to those obtained with classic techniques, expanding the surgical indications for these fractures. ${ }^{12,13}$

The present study evaluates outcomes from nondisplaced acute or subacute hook fractures in four patients treated percutaneously with a conical cannulated screw.

\section{Material and Methods}

This is a retrospective study with patients who underwent surgery for hamate fractures from September 2008 to June 2019. The inclusion criteria were as follows: (1) fracture of the hook of hamate; (2) age ranging from 18 to 65 years; and (3) a minimum follow-up period of 6 months. A total of four patients were included, all men.

We reviewed the demographic data, hand dominance, and mechanism of injury; in addition, we recorded the duration and type of symptoms, ancillary tests performed, and type and time of surgery. All patients answered the quick disabilities of the arm, shoulder, and hand (QuickDASH) questionnaire and had their strength evaluated with a Jamar (JLW Instruments, Chicago, USA) hydraulic dynamometer before and after the surgery. In addition, radiographs (anteroposterior [AP], lateral, and carpal tunnel views) and any records from the follow-up period were analyzed, including potential complications, immobilization time, and return to work activities. We used the Milch classification system modified by Hirano and Inoue ${ }^{10}$ for fractures of the hook of hamate. This system differentiates fractures into two types: type 1 includes hook of hamate fractures, while type 2 includes 
hamate body fractures. The latter are divided into type 2a, which is a coronal fracture of the body, and type $2 \mathrm{~b}$, which is a transverse fracture of the body. ${ }^{10}$ Two investigators (B. O. G. and V.H.S.) performed the data collection. The Wilcoxon test for paired samples was used to compare pre and postoperative strength, and the Wilcoxon paired rank test was used to compare QuickDASH scores. All patients consented to participate in this retrospective study.

\section{Surgical Technique}

All patients received a conical headless screw (Acutrak 2 Mini, Acumed, Hillsboro, OR, USA). This cannulated screw has a $3.5-\mathrm{mm}$ diameter tip and a $3.6-\mathrm{mm}$ thread allowing passage through $1.1-\mathrm{mm}$ guidewires. In our study, three screws were $20-\mathrm{mm}$ long, and one was 22-mm long.

Following the technique described by Scheuffler et al. ${ }^{12}$ and Nanno et al., ${ }^{13}$ the surgery was performed with a brachial plexus block. The hook of hamate was marked under arthroscopic control in a posteroanterior (PA) projection. The incision had approximately $0.5 \mathrm{~cm}$; a blunt dissection was made with mosquito forceps or scissors until reaching the bone surface to separate the extensor muscles. Next, a 1.1-mm Kirschner wire was introduced on the center of the hamate, slightly proximal to it (-Fig. 1A). Under arthroscopic control, the Kirschner wire was advanced towards the center of the ring forming the hook of hamate in anteroposterior (AP) view. As described by Scheufler et al., ${ }^{12}$ a $45^{\circ}$ oblique view was made with the wrist in mild extension and radial deviation (-Fig. 1B); alternatively, use a Hart carpal tunnel view. This image confirmed that the Kirschner wire reached the tip of the hook without exceeding it, thus preventing its displacement. A second, temporary Kirschner wire was inserted to prevent malrotation during screw insertion ( - Fig. 2). Then, the length of the conical screw was determined; since the screw has to be in a subcortical position without exceeding the tip of the hamate, it is advisable to subtract $2 \mathrm{~mm}$ from the measurement obtained. The dorsal cortex of the hamate was drilled with a 2-mm fluted bit to maintain the Kirschner wire fixation and reduction. Finally, the screw was passed to the desired length, checking fracture compression and reduction with radiological controls in PA, lateral, carpal tunnel, and $45^{\circ}$ oblique views (-Fig. 3, - Fig. 4). The Kirschner wires were removed, and the wound was sutured.

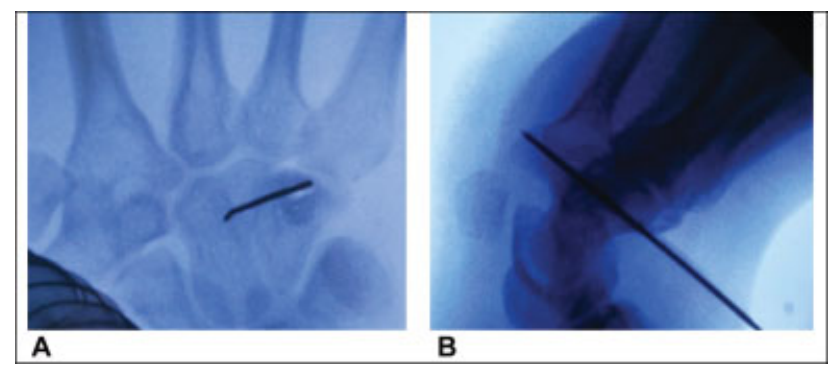

Fig. 1 (A) 1.1-mm Kirschner wire centered on the hamate and inserted slightly proximal to it. (B) $45^{\circ}$ oblique view with the wrist in slight extension and radial deviation.
Two patients used a long arm cast (up to the $4^{\text {th }}$ and $5^{\text {th }}$ fingers) for 2 weeks after surgery; the 2 other patients used it for 3 weeks. This was followed by free wrist mobilization. At 2 months postsurgery, all patients were able to carry out daily life and sports activities. The radiographic control revealed consolidation in all cases at 3 to 6 months.

\section{Results}

For diagnostic purposes, the AP and lateral radiographs performed in all patients revealed no evidence of fracture; in two cases, a Hart carpal tunnel view allowed fracture visualization. All patients underwent a computed tomography (CT) scan for lesion confirmation (-Fig. 5). All patients had a type I, nondisplaced fracture according to the Milch

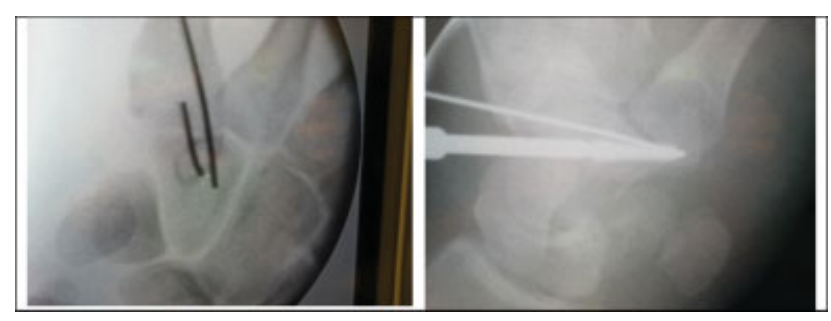

Fig. 2 Temporary Kirschner wire to prevent malrotation during screw insertion.

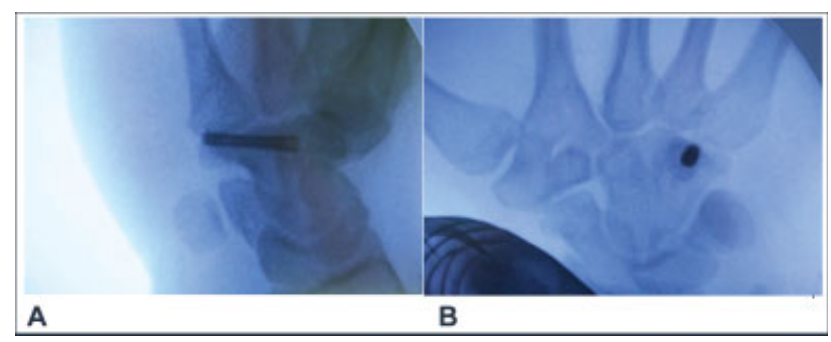

Fig. 3 Arthroscopic controls after conical screw insertion. (A) $45^{\circ}$ oblique view. (B) Posteroanterior view.

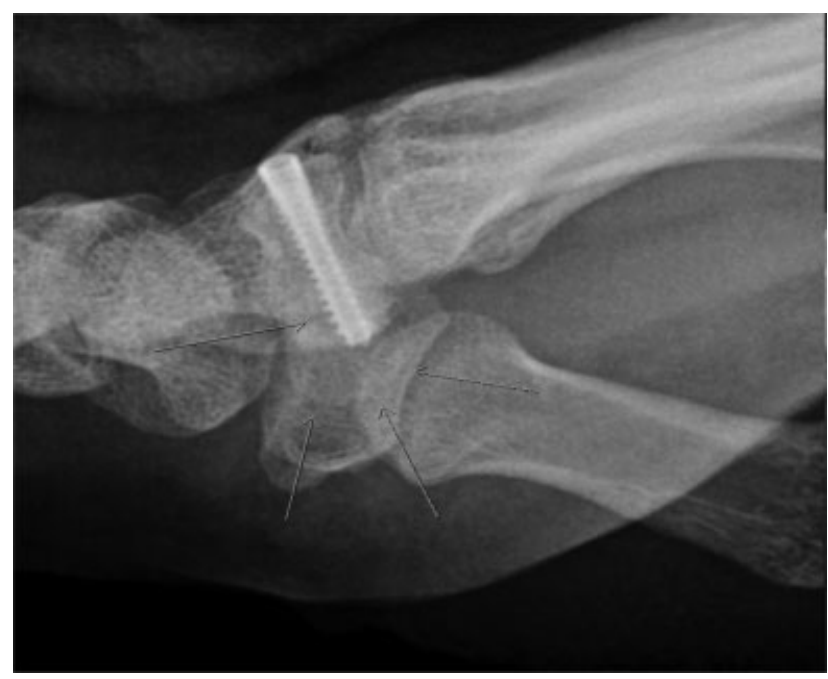

Fig. 4 Follow-up radiograph. Arrows indicate the hook of hamate limits. 


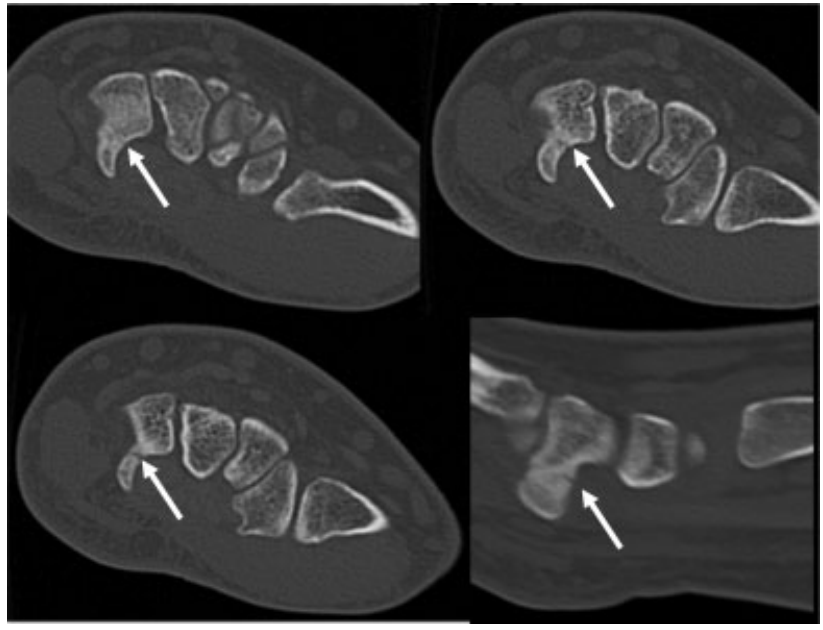

Fig. 5 Computed tomography images showing a fracture at the base of the hook of hamate (arrows).

classification modified by Hirano and Inoue. ${ }^{10}$ All patients reported pain at the ulnar edge of the wrist, as well as under load (-Table 1). The pull test was positive in half of the patients, and three of them also presented hamate pain.

Although the strength measured with the Jamar dynamometer showed a trend towards improvement, there was no statistical significance (-Fig. 6).

Since the sample consisted of four patients only, the QuickDASH scores analysis used median and $25^{\text {th }}$ (P25) and $75^{\text {th }}$ percentile (P75) values. The median QuickDASH score was 29 (P25: 21; P75: 29) before surgery and 0.8 (P25: 0 ; P75: 0.8 ) after the procedure. The $p$-value was 0.068 , and data analysis used the Wilcoxon paired ranks test.

\section{Case 1}

The patient was a 21-year-old, right-handed male presenting no relevant history. He reported pain at the ulnar margin of the wrist and inability to grasp objects one month after trauma in his left (non-dominant) hand. On examination, the patient presented hamate pain and a positive pull test. The AP and lateral radiographs were nondiagnostic, and a carpal tunnel view showed the hook of the hamate fracture. A CT scan completed the diagnostic study. Osteosynthesis with a 22-mm Acutrak 2 Mini screw proceeded as previously described. The patient used a cast for 3 weeks. Six months after

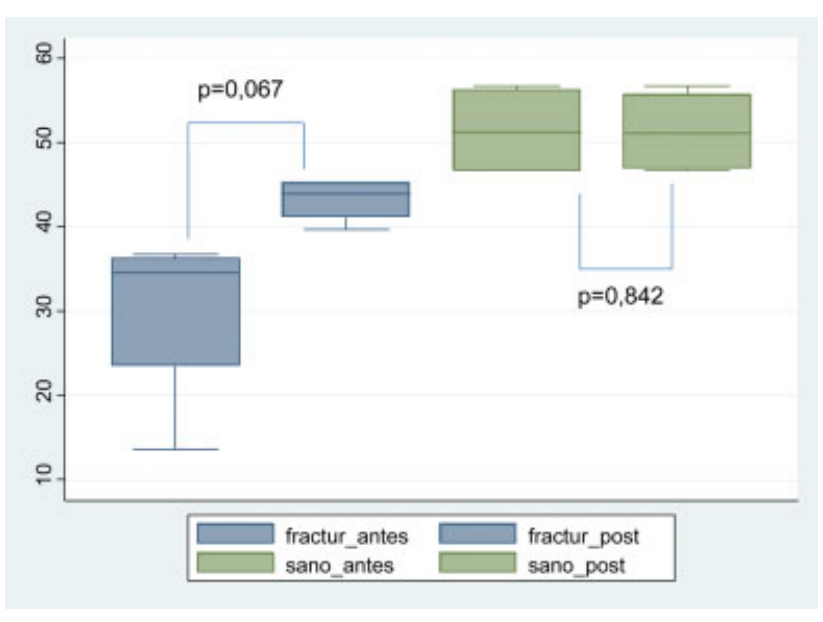

Fig. 6 Wilcoxon test for paired samples showing the differences in strength measured with a JAMAR dynamometer before and after surgery in operated (blue) and non-operated (green) hands. Operated patients present improved strength $(\mathrm{Kg})$ but with no statistical significance $(p=0.067)$. Fracture pre: strength on the fractured side before surgery; Fracture post: strength on the fractured side after surgery; Healthy pre: strength on the healthy side before surgery; Healthy post: strength on the healthy side after surgery

the surgery, the baseline QuickDASH score went from 81 to 4.5 , and the average strength went from $13.7 \mathrm{~kg}$ to $45.3 \mathrm{~kg}$ (-Table 2). There were no intercurrences during the followup period (12 months).

\section{Case 2}

The patient was a 21-year-old, right-handed male, professional golf player, with no relevant history. He reported pain at the ulnar edge of the wrist when playing golf or during pronation-supination movements for 9 months in his left (non-dominant) hand. On examination, the patient presented hamate pain. The AP and lateral radiographs were nondiagnostic, and a carpal tunnel view showed a fracture at the hook of hamate. A CT scan completed the diagnostic study, revealing a fracture in pseudoarthrosis with no displacement. Osteosynthesis with a 20-mm Acutrak 2 Mini screw proceeded as previously described. The patient used a cast for 3 weeks. Seven months after the surgery, the baseline QuickDASH score went from 23 to 14 , and the average strength went from $36 \mathrm{~kg}$ to $42.7 \mathrm{~kg}$ (-Table 2).

Table 1 Summary of patients included in the study

\begin{tabular}{|l|l|l|l|l|l|l|l|l|}
\hline PATIENT & AGE & GENDER & \multicolumn{2}{l|}{ SIDE } & MECHANISM & \multicolumn{2}{l|}{ PAIN } \\
\hline & & & $\begin{array}{l}\text { Affected } \\
\text { side }\end{array}$ & $\begin{array}{l}\text { Dominant } \\
\text { hand }\end{array}$ & & Ulnar & $\begin{array}{l}\text { Grasping } \\
\text { Pronation- } \\
\text { supination against } \\
\text { resistance }\end{array}$ \\
\hline 1 & 21 & Male & Left & Right & Direct trauma & + & + & - \\
\hline 2 & 21 & Male & Left & Right & Golf & + & + & + \\
\hline 3 & 42 & Male & Left & Right & Motorcycle accident & + & + & + \\
\hline 4 & 23 & Male & Left & Right & Bicycle accident & + & + & + \\
\hline
\end{tabular}

Age in years. Present $(+)$; not present (-). 
There were no intercurrences during the follow-up period (12 months).

\section{Case 3}

The patient was a 42-year-old, right-handed male presenting no relevant history. He reported pain in the ulnar aspect of the right wrist since a low-energy motorcycle accident a month earlier. The AP and lateral radiographs taken at the emergency room after the accident were normal. A CT scan confirmed a hook of hamate fracture. The surgery proceeded with a 20-mm Acutrak 2 Mini screw as previously described. The patient used a cast for 2 weeks. Six months after surgery, the baseline QuickDASH score went from 35 to 0 , and the average strength went from $36.7 \mathrm{~kg}$ to $45.3 \mathrm{~kg}$ (- Table 2). There were no intercurrences during the follow-up period (14 months).

\section{Case 4}

The patient was a 23-year-old, right-handed, radiological technician male presenting no relevant history. He went to an outpatient clinic 3 months after falling from a bicycle while holding the handlebars. The patient reported pain in the ulnar aspect that increased under load and when grabbing objects. He presented hamate pain and a positive pull test. The AP, lateral, and carpal tunnel radiographs were normal. A magnetic resonance imaging (MRI) and a CT scan revealed a fracture of the hook of hamate on the left hand, with no other injuries. Osteosynthesis with a $20-\mathrm{mm}$ Acutrak 2 Mini screw proceeded as previously described. The patient used a cast for 2 weeks. Six months after the surgery, the baseline QuickDASH score went from 18 to 0; at 3 months, the average strength went $33.3 \mathrm{~kg}$ to $39.7 \mathrm{~kg}$. There were no intercurrences during the follow-up period (16 months).

\section{Discussion}

\section{Epidemiology and Mechanism of Injury}

Hook of hamate fractures are rare, accounting for 2 to $4 \%$ of carpal fractures. Not all patients with hamate fractures seek medical attention, as some are asymptomatic; therefore, the real incidence of these fractures remains unknown. ${ }^{1-3}$

A fracture of the hook of hamate does not require a highenergy trauma. A direct trauma, grasping an object, or repeated trauma in sports can cause a stress fracture. Because of its injury mechanism, it is a frequent type of fracture in sports that require a strong grip, often in the non-dominant hand. ${ }^{4-6}$ Falls over an extended wrist with ulnar deviation and severe contraction of the flexor muscles of the fourth and fifth fingers or traction of the pisohamate ligament can also cause a baseline fracture or an avulsion fracture of the tip of the hook of hamate, respectively. 5,14

In our series, two fractures resulted from falls while holding a handlebar, one resulted from direct trauma, and one was an indirect injury on the non-dominant hand of a golf player. These four cases highlight the several possible injury mechanisms of this type of fracture.

Fractures located at the base and proximal third of the hook are the most frequent (76\%); they are usually 
nondisplaced. Our study includes only type 1 , nondisplaced fractures according to the Milch classification modified by Hirano and Inoue. ${ }^{5,10}$

\section{Diagnosis}

A diagnostic suspicion, proper history taking, and physical examination are critical for diagnosis. Ulnar pain, paresthesia at the ulnar nerve territory, decreased grip strength, and even difficult fourth and fifth fingers mobilization are consistent findings. ${ }^{8}$ The pull test is positive when pain is elicited in fourth and fifth finger flexion against resistance with the wrist in dorsoulnar deviation; its sensitivity ranges from 72 to $100 \%{ }^{8,15}$ In our series, the pull test was positive in patients submitted to it (two out of four), while ulnar carpal region pain was a constant finding observed in previous studies. $^{8}$

Diagnosis is usually late because these fractures are difficult to identify in usual AP and lateral radiographs. ${ }^{4,5,7,8}$ The Hart carpal tunnel view is especially useful in this type of injury; its sensitivity ranges from 40 to $50 \%$, although it is painful in the acute phase. ${ }^{3,6-8}$ In our series, $50 \%$ of the fractures were identified with this view. We believe that it is an essential part of the diagnostic work-up.

In some series, the average time from injury to diagnosis is 22 to 24 weeks; in recent decades, it decreased to 4 weeks thanks to MRI and CT. ${ }^{1,2,6,8}$ In our series, the diagnosis of patients with a direct traumatic history took 23 to 30 days; in the only case of repeated microtrauma, diagnosis occurred after 9 months. Magnetic resonance imagin is superior to CT in nondisplaced fractures; however, since CT is more available and cheaper, it is usually the test of choice when suspicion is high. ${ }^{5,8}$ Care by hand surgeons, like us, also tends to decrease this time. . $^{8,16}$

Bansal et al. ${ }^{4}$ reported that late diagnosis increases the risk of postoperative complications after hook of hamate resection, especially transient ulnar neuropathy. Painful scars were also reported, all with resolution after 6 to 12 months. $^{4}$

\section{Treatment}

The initial treatment can be conservative, in the case of acute nondisplaced fractures, although the pseudoarthrosis rate ranges from 30 to $80 \%$ in different series, ${ }^{1,2,17}$ resulting in immobilization for approximately 8 weeks.

Surgical treatment is usually reserved for displaced fractures, delayed union, painful non-unions, or athletes; classical techniques include hook resection or open reduction and internal fixation. Although the debate over the best option continues, hook resection is favored because recovery is faster; in addition, there are no clear differences in functional outcomes. ${ }^{4,18}$ However, other authors ${ }^{16,18,19}$ believe that hamate resection reduces the grip strength of the fourth and fifth fingers, as the hook acts as a fulcrum for their deep flexor muscles; on the other hand, the excursion of the flexor muscles from these fingers would decrease by $11 \%$. For both techniques, surgical dissection is extensive, and risks include damage to the ulnar nerve or the intrinsic muscles of the fifth finger and decreased vascular supply to the soft tissues and the hook of hamate. ${ }^{4}$ Open reduction and synthesis of the hook of hamate is not an easy procedure.

As such, during the last decade, minimally invasive dorsal percutaneous techniques have been introduced with synthesis using Acutrak-type conical cannulated screws (Acumed), resulting in functional and radiological outcomes similar to those observed with classical techniques. ${ }^{12,13}$ The surgical approach is safe, and the incision is only $1 \mathrm{~cm}$ long, reducing the risk of painful scars and sparing ligaments adjacent to the hamate bone. At first, the postoperative immobilization time was 3 weeks, but it was shortened to 2 weeks to allow earlier mobilization. Fine manual activity is allowed from the second postoperative week on, and patients can progressively resume their daily life activities. Since this technique allows return to sports in 2 to 3 months, it is also an alternative for professional athletes. From a functional point of view, hook of hamate fixation sustains digital strength, especially in ulnar deviation, as reflected in JAMAR measurements (-Table 2). Operated patients presented improved strength and QuickDASH scores, although with no statistical significance (-Fig. 6). The functional outcomes and QuickDASH scores from our study are excellent and consistent with more classical techniques. When questioned, all patients reported they would undergo surgery again.

\section{Conclusion}

With our study, we concluded that the surgical treatment of hook of hamate fractures using a dorsal percutaneous approach is safe and effective. Our short series included a nondisplaced fracture of the hook of hamate in pseudoarthrosis; there were no more known cases of pseudoarthrosis in our study, and more cases would be required to draw conclusions with greater certainty.

Despite these promising results, our study had a limited sample and no control group; as such, new randomized studies with more patients are required to draw conclusions with greater confidence.

\section{Data Confidentiality}

The authors declare that they have followed the protocols of their work center on the publication of patient data. All patients complied with their inclusion in this study, signing the corresponding informed consent form.

\section{Funding}

This research has not received specific aid from public agencies, commercial or non-profit entities.

\section{Conflict of Interests}

The authors have no conflict of interests to declare.

\section{References}

1 Scheufler O, Radmer S, Erdmann D, Germann G, Pierer G, Andresen R. Therapeutic alternatives in nonunion of hamate hook fractures: personal experience in 8 patients and review of literature. Ann Plast Surg 2005;55(02):149-154. Doi: 10.1097/01. sap.0000168697.05149.75 
2 David TS, Zemel NP, Mathews PV. Symptomatic, partial union of the hook of the hamate fracture in athletes. Am J Sports Med 2003; 31(01):106-111. Doi: 10.1177/03635465030310010201

3 Sarabia Condés JM, Ibañez Martínez L, Sánchez Carrasco MA, Carrillo Julia FJ, Salmerón Martínez EL. Hamate fractures. Rev Esp Cir Ortop Traumatol 2015;59(05):299-306. Doi: 10.1016/j. recot.2015.02.003

4 Bansal A, Carlan D, Moley J, Goodson H, Goldfarb CA. Return to Play and Complications After Hook of the Hamate Fracture Surgery. J Hand Surg Am 2017;42(10):803-809. Doi: 10.1016/j. jhsa.2017.06.108

5 Mouzopoulos G, Vlachos C, Karantzalis L, Vlachos K. Fractures of hamate: a clinical overview. Musculoskelet Surg. 2019 Apr;103 (1):15-21. doi: 10.1007/s12306-018-0543-y. Epub 2018 May 29. PMID: 29845407

6 Bishop AT, Beckenbaugh RD. Fracture of the hamate hook.J Hand Surg Am 1988;13(01):135-139. Doi: 10.1016/0363-5023(88)90217-1

7 Cecava ND, Finn MF, Mansfield LT. Subtle radiographic signs of hamate body fracture: a diagnosis not to miss in the emergency department. Emerg Radiol 2017;24(06):689-695. Doi: 10.1007/ s10140-017-1523-5

8 Kadar A, Bishop AT, Suchyta MA, Moran SL. Diagnosis and management of hook of hamate fractures. J Hand Surg Eur Vol 2018;43(05):539-545. Doi: 10.1177/1753193417729603

9 Failla JM. Hook of hamate vascularity: vulnerability to osteonecrosis and nonunion. J Hand Surg Am 1993;18(06):1075-1079. Doi: 10.1016/0363-5023(93)90405-R

10 Hirano K, Inoue G. Classification and treatment of hamate fractures. Hand Surg 2005;10(2-3):151-157
11 Tolat AR, Humphrey JA, McGovern PD, Compson J. Surgical excision of ununited hook of hamate fractures via the carpal tunnel approach. Injury 2014;45(10):1554-1556. Doi: 10.1016/j.injury.2014.05.008

12 Scheufler O, Radmer S, Andresen R. Dorsal percutaneous cannulated mini-screw fixation for fractures of the hamate hook. Hand Surg 2012;17(02):287-293. Doi: 10.1142/S0218810412970039

13 Nanno M, Sawaizumi T, Ito H. Simplified dorsal approach to fracture of the hamate hook with percutaneous fixation with screws. J Plast Surg Hand Surg 2010;44(4-5):214-218. Doi: 10.3109/02844310801956714

14 Bachoura A, Wroblewski A, Jacoby SM, Osterman AL, Culp RW. Hook of hamate fractures in competitive baseball players. Hand (N Y) 2013;8(03):302-307. Doi: 10.1007/s11552-0139527-4

15 Wright TW, Moser MW, Sahajpal DT. Hook of hamate pull test. J Hand Surg Am 2010;35(11):1887-1889. Doi: 10.1016/j. jhsa.2010.08.024

16 Klausmeyer MA, Mudgal CS. Hook of hamate fractures. J Hand Surg Am 2013;38(12):2457-2460, quiz 2460

17 Carroll RE, Lakin JF. Fracture of the hook of the hamate: acute treatment. J Trauma 1993;34(06):803-805

18 Demirkan F, Calandruccio JH, Diangelo D. Biomechanicalvaluation of flexor tendon function after hamate hook excision. J Hand Surg Am 2003;28(01):138-143. Doi: 10.1053/ jhsu.2003.50005

19 Watson HK, Rogers WD. Nonunion of the hook of the hamate: an argument for bone grafting the nonunion. J Hand Surg Am 1989; 14(03):486-490. Doi: 10.1016/S0363-5023(89)80008-5 